\title{
MAP2 is a Component of Crossbridges Between Microtubules and Neurofilaments in the Neuronal Cytoskeleton: Quick-Freeze, Deep- Etch Immunoelectron Microscopy and Reconstitution Studies
}

\author{
Nobutaka Hirokawa, Shin-Ichi Hisanaga, and Yoko Shiomura \\ Department of Anatomy and Cell Biology, School of Medicine, University of Tokyo, Hongo, Tokyo, 113 Japan
}

\begin{abstract}
Microtubules (MT) and neurofilaments (NF) are linked by frequent crossbridges in situ. In order to answer the question of what makes these crossbridges, we performed the immunogold procedure on rat spinal cord motor neurons using an affinity-purified polyclonal antibody against rat brain MAP2 and gold-labeled anti-rabbit IgG goat IgG. A quick-freeze, deep-etch technique (QF-DE) in conjuction with decoration with anti-MAP2 antibody and ferritin-labeled second antibody was also used. In motor neuron dentrites crossbridges were clearly displayed between MTs and NFs by QF-DE. These crossbridges were revealed in thin sections as fuzzy filamentous structures between MT and NF. Gold particles studded the fuzzy structures associated with MT. Many such structures connected MTs to NFs. Furthermore, antibody complexes containing ferritin were localized on the crossbridges between MTs and NFs by the QF-DE study. In addition, we performed reconstitution experiments. We isolated $70 \mathrm{kDa}(L)$ protein of neurofilaments from calf spinal cords and assembled $L$ to form neurofilaments in vitro. MAP2 bound these neurofilaments according to both SDS-PAGE and QF-DE electron microscopy of the pellets of suspensions containing $L$ proteins and MAP2. When we added tubulin to this suspension and polymerized it in the presence of taxol, neurofilaments were crosslinked with microtubules by MAP2 crossbridges. Hence, from these 2 approaches we concluded that MAP2 is a component of crossbridges between MTs and NFs in the neuronal cytoskeleton in vivo and in vitro.
\end{abstract}

Recently it has been revealed that there is an extensive system of crossbridges between cytoskeletal elements in nerve cells (Ellisman and Porter, 1980; Hirokawa, 1982). In previous studies these crossbridges were categorized into 3 groups: NF-associated cross-linkers (NF-NF), MT-associated crossbridges (MT-MT, MT-NF, MT-membrane organelles), and long crosslinks in the subaxolemmal space (Hirokawa, 1982; Hirokawa and Yorifuji,

\footnotetext{
Received June 29, 1987; revised Dec. 15, 1987; accepted Dec. 15, 1987.

We wish to thank Drs. Y. Ihara and H. Mori at the Tokyo Metropolitan Institute of Gerontology for providing affinity-purified anti-MAP2 antibody. We are grateful to Ms. Y. Kawasaki for her secretarial assistance and to Mr. Y. Fukuda for his photographic expertise. This work was supported in part by Grants-in-Aid from the Ministry of Education, Science and Culture of Japan and a grant from the Muscular Dystrophy Association of America to N.H.

Correspondence should be address to Dr. Nobutaka Hinokawa at the above address.

Copyright $@ 1988$ Society for Neuroscience $0270-6474 / 88 / 082769-11 \$ 02.00 / 0$
}

1986). In order to understand the functions of these crossbridges it is necessary to determine their chemical nature as first step. It has been demonstrated by immunocytochemistry or antibody decoration in conjunction with quick-freeze, deep-etch study that neurofilament $200 \mathrm{~K}$ protein is a component of crossbridges between NFs in the axon (Hirokawa et al., 1984). In terms of the crossbridges between MTs and MTs, microtubule-associated protein 1 (MAP1) has been proven to be a major component in the axon (Hirokawa et al., 1985), while in dendrites crossbridges between microtubules comprise both MAP1 and MAP2 (Shiomura and Hirokawa, 1987a, b).

However, the nature of other crosslinkers, such as between MT and NF and between MO and MT, has been largely unknown. In vitro studies have suggested that interaction between M'l's and NFs could be mediated by high-molecular-weight MAPs (Leterrier et al., 1981, 1982; Williams and Aamodt, 1985) or MAP2 (Miyata ct al., 1986). Another biochemical study in vitro indicated that $200 \mathrm{~K}$ neurofilament protein could crosslink MTs with NFs (Minami and Sakai, 1983). Bloom and Vallee (1983) observed that a monoclonal antibody to MAP2 distributed itself with MTs in (non-neuronal) glial cells but that when the microtubules were destroyed by vinblastine the same antibody was found with the (vimentin) intermediate filaments, indicating that MAP2 is found in association with both MTs and intermediate filaments. Papasozomenos et al. (1985) demonstrated that anti-MAP2 monoclonal antibodies stained either the neurofilament domain or the microtubule domain in the IDPN-intoxicated rat peripheral axon by peroxidase-antiperoxidase staining.

However, because of limitations of resolution of the techniques employed in the previous studies, the question of what forms crossbridges between MTs and NFs has not been answered. The use of colloidal gold as a marker of the protein enables us to study its precise localization. In the present study we performed immunocytochemical analysis and antibody decoration in situ in conjunction with the QF-DE method on rat spinal cord motor neurons using anti-rat MAP2 affinity-purified polyclonal antibody and gold-labeled anti-rabbit IgG goat IgG or a ferritin-labeled second IgG. Furthermore, we carried out reconstitution studies in vitro using neurofilaments composed of $70 \mathrm{kDa}$ protein, MAP2, and tubulin. Both the immunogold procedure and the QF-DE study indicated that MAP2 is a component of crossbridges between MTs and NFs in situ. This conclusion was further supported by reconstitution studies, which indicated that MAP2 formed crossbridges between NFs and MTs in vitro. 


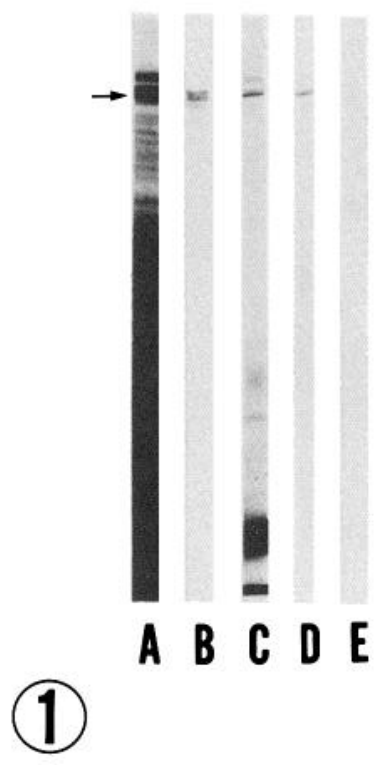

Figure 1. Immunoblotting of rat microtubule proteins using affinitypurified anti-rat brain MAP2 IgG. SDS-PAGE of rat brain crude extract $(A)$ and rat brain microtubule proteins $(C)$ stained with CBB. Staining of the blots of crude brain extract $(B)$, microtubule proteins $(D$ and $E)$ with anti-MAP2 $\operatorname{IgG}(B$ and $D)$ or nonimmune $\operatorname{IgG}(E)$. This antiMAP2 IgG stained bands of MAP2 strongly (arrow).

\section{Materials and Methods}

\section{Antibody characterization}

Affinity-purified rabbit polyclonal antibody $(\mathrm{PcAb})$ against rat brain MAP was provided by Dr. Yasuo Ihara (Tokyo Metropolitan Institute of Gerontology). This polyclonal antibody was purified through an affinity column using rat brain MAP2. The immunoreactive proteins were identified on polyacrylamide gel blots (Towbin et al., 1979). Rat brain crude extracts and rat brain MT proteins prepared by the taxol method (Vallee, 1982) were applied to 7\% SDS-PAGE according to Laemmli (1970) and then blotted on nitrocellulose paper.

\section{Immunofluorescence microscopy}

The lumbar regions of spinal cords were dissected from rats perfused with $2 \%$ paraformaldehyde, $0.1 \%$ glutaraldehyde in PEM buffer, $\mathrm{pH} 6.8$
(100 mм Pipes, 1 mm EGTA, $1 \mathrm{~mm} \mathrm{MgCl}_{2}$ ). Immunofluorescence microscopy was carried out using rabbit PcAb against MAP2 or nonimmune rabbit IgG as control and fluorescein-conjugated anti-rabbit IgG goat IgG (Cappel Laboratories) as described in our previous studies (Shiomura and Hirokawa, 1987a, b).

\section{Immunoelectron microscopy and $Q F-D E$ electron microscopy}

The lumbar region of a rat spinal cord was removed and cut into thin slices $(\sim 300 \mu \mathrm{m})$ by a microslicer in $\mathrm{Ca}^{+}$-free rat Ringer $(155 \mathrm{~mm} \mathrm{NaCl}$, $5 \mathrm{mM} \mathrm{KCl}, 5 \mathrm{mM} \mathrm{MgCl}_{2}, 0.5 \mathrm{mM} \mathrm{NaH}_{2} \mathrm{PO}_{4}, 3 \mathrm{mM}$ EGTA, and $5 \mathrm{~mm}$ HEPES at $\mathrm{pH} 7.0$ ) containing $1 \mu \mathrm{g} / \mathrm{ml}$ leupeptin. The slices were incubated with $1 \%$ Triton X-100 in a fixative ( $2 \%$ paraformaldehyde, $0.1 \%$ glutaraldehyde, $10 \mu \mathrm{M}$ taxol in PEM buffer, $\mathrm{pH}$ 6.8) for $40 \mathrm{~min}$ at room temperature. They were transferred to a fixative without Triton $\mathrm{X}-100$ and fixed for a total of $2 \mathrm{hr}$. After being rinsed with buffer (4\% sucrose in $0.1 \mathrm{M}$ phosphate buffer, $\mathrm{pH} 7.4$ ), the anterior horn regions were dissected with razorblades. Then the small pieces of tissue slices were incubated with $1 \% \mathrm{NaBH}_{4}$ in rinse buffer.

Next, the following incubation procedures for immunostaining were carried out. The samples were incubated with $20 \%$ goat serum in Tris buffer saline (TBS; $20 \mathrm{~mm}$ Tris, $0.9 \% \mathrm{NaCl}$ ), $\mathrm{pH} 7.6$, for $3 \mathrm{hr}$ at room temperature to block nonspecific reactions. Incubation with the first Abs (either anti-MAP2 PcAb or normal rabbit IgG as control) was continued for a total of $19 \mathrm{hr}$ at room temperature and/or at $4^{\circ} \mathrm{C}$. The

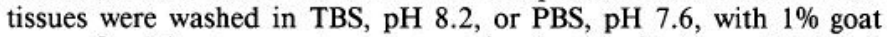
serum for $1 \mathrm{hr}$ at room temperature, incubated with the gold-labeled second Abs (5 nm gold-conjugated goat IgG anti-rabbit IgG; Jansen Pharmaceutica, Beerse, Belgium) or ferritin-labeled second Abs (ferritinconjugated goat IgG anti-rabbit IgG; Miles Yeda, Israel) for a total of $19 \mathrm{hr}$, and then washed again in TBS, pH 8.2, for gold-labeled second Abs with $1 \%$ goat serum for $1 \mathrm{hr}$. Some of the tissues were fixed and embedded by conventional procedures for electron microscopy. Some of the slices incubated with ferritin-labeled second Abs were quickfrozen with a machine cooled by liquid helium, fractured, and deepetched as described previously (Heuser and Salpeter, 1979; Hirokawa and Heuser, 1981). After rotary shadowing, the tissues were dissolved in chromsulfuric acid. The ultrathin sections and replicas were observed with a JEOL 2000EX electron microscope at $100 \mathrm{keV}$. Unfixed slices of rat spinal cord were also quick-frozen, deep-etched and observed by electron microscopy.

\section{Reconstitution study}

Isolation of $70 \mathrm{kDa}$ molecular mass protein. Neurofilaments from calf spinal cords were isolated, solubilized with $8 \mathrm{~m}$ urea and fractionated by anion-exchange chromatography on DEAE-cellulose as described by Geisler and Weber (1981). The triplet proteins were further purified by
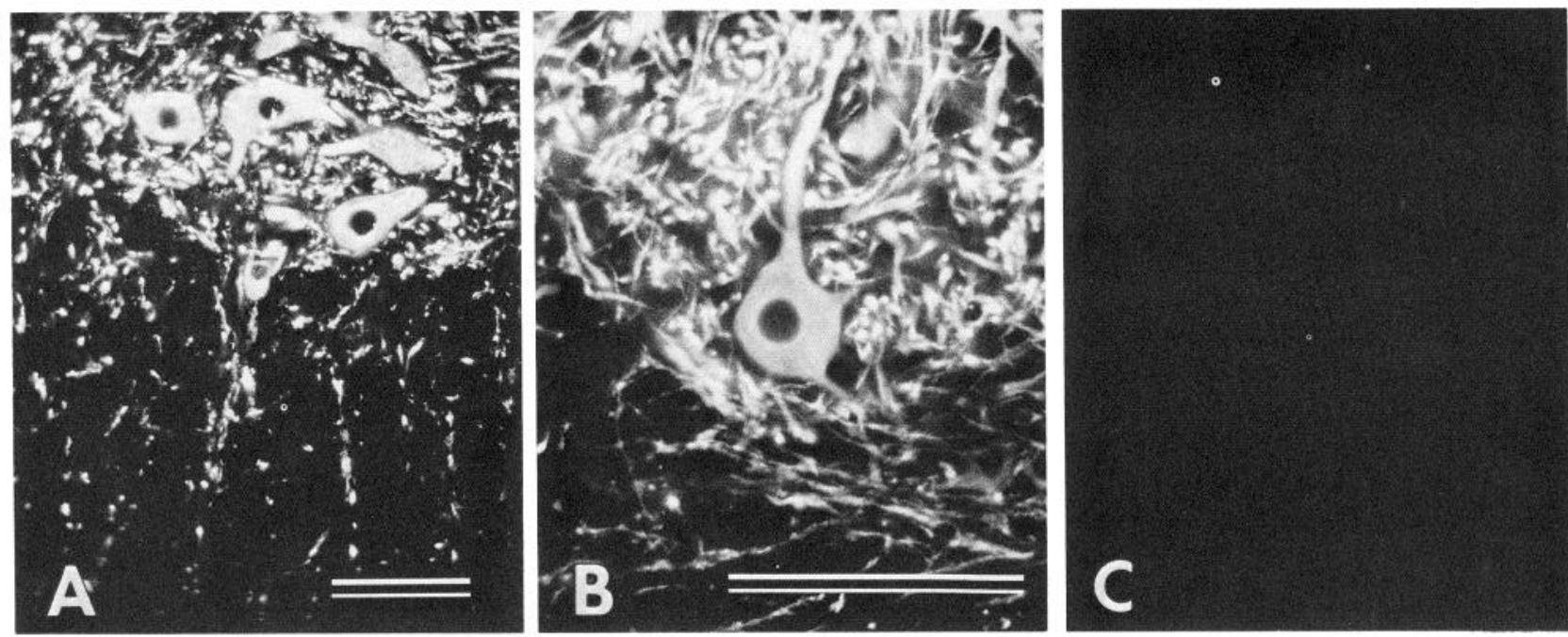

Figure 2. Immunofluorescence microscopy of the anterior horn region of rat spinal cord stained with anti-MAP2 IgG $(A, B)$ or nonimmune IgG (C). Cell bodies and dendrites of motor neurons are intensively stained, while white matter (the lower half of $A$ ) was not stained. Scale bars, 100 $\mu \mathrm{m}$. 


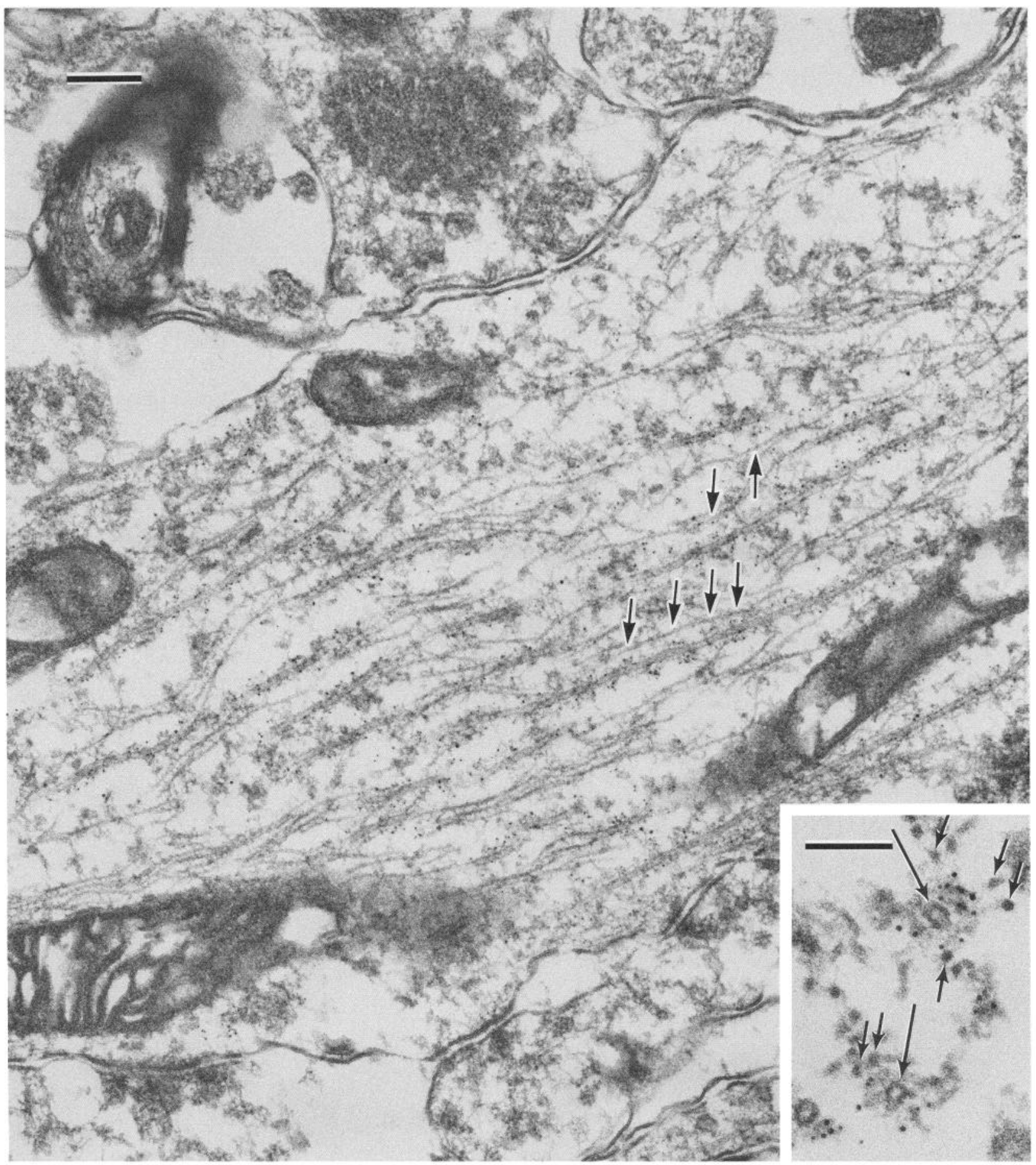

Figure 3. A motor neuron dendrite stained with anti-MAP2 IgG and gold (5 nm) labeled second antibody. Overall cytoskeletal architecture is well preserved. Immunogold particles are studded on fuzzy structures associated with MTs. Many gold particles decorate filamentous structures between NFs and MTs (arrows). Scale bar, $0.2 \mu \mathrm{m}$. Inset, Cross-sectional view of a dendrite. NFs (short arrows) run close to MTs (long arrows). Gold particles decorate fuzzy structures between NFs and MTs. Scale bar, $0.1 \mu \mathrm{m}$.

a Mono Q anion exchanging column (Pharmacia Fine Chemicals, Uppsala, Sweden). We obtained purified $70 \mathrm{kDa}$ protein $(3.0 \mathrm{mg} / \mathrm{ml})$.

Isolation of tubulin. Tubulin was prepared from porcine brain by phosphocellulose chromatography (Weingarten et al., 1975).

Isolation of MAP2. Microtubule proteins were obtained from rat brains by cycles of temperature-dependent assembly and disassembly (Shelanski et al., 1973). Supernatants of the first cycle $(32 \mathrm{ml})$ were boiled at $95^{\circ} \mathrm{C}$ for $5 \mathrm{~min}$ in the presence of $0.75 \mathrm{M} \mathrm{NaCl}, 2 \mathrm{~mm}$ DTT, $1 \mathrm{~mm}$ PMSF and were then centrifuged at $80,000 \times g$ for $40 \mathrm{~min}$ at $4^{\circ} \mathrm{C}$. Proteins in the supernatants were sedimented by adding ammonium sulfate to $50 \%$ saturation and centrifuged at $80,000 \times g$ for $45 \mathrm{~min}$ at $4^{\circ} \mathrm{C}$. The pellet was dissolved into $2 \mathrm{ml}$ of $20 \mathrm{~mm}$ Pipes, $1 \mathrm{~mm} \mathrm{MgCl}_{2}, 1 \mathrm{~mm}$ EGTA, $0.75 \mathrm{M} \mathrm{NaCl}, \mathrm{pH} 6.8$, and was dialyzed against the same buffer. After centrifugation at $150,000 \times g$ for $30 \mathrm{~min}$ at $4^{\circ} \mathrm{C}$, the suspension was applied to a Superose 6 prep grade gel filtration column (Pharmacia Fine Chemicals, Uppsala, Sweden). After MAP2 was successfully puri- 

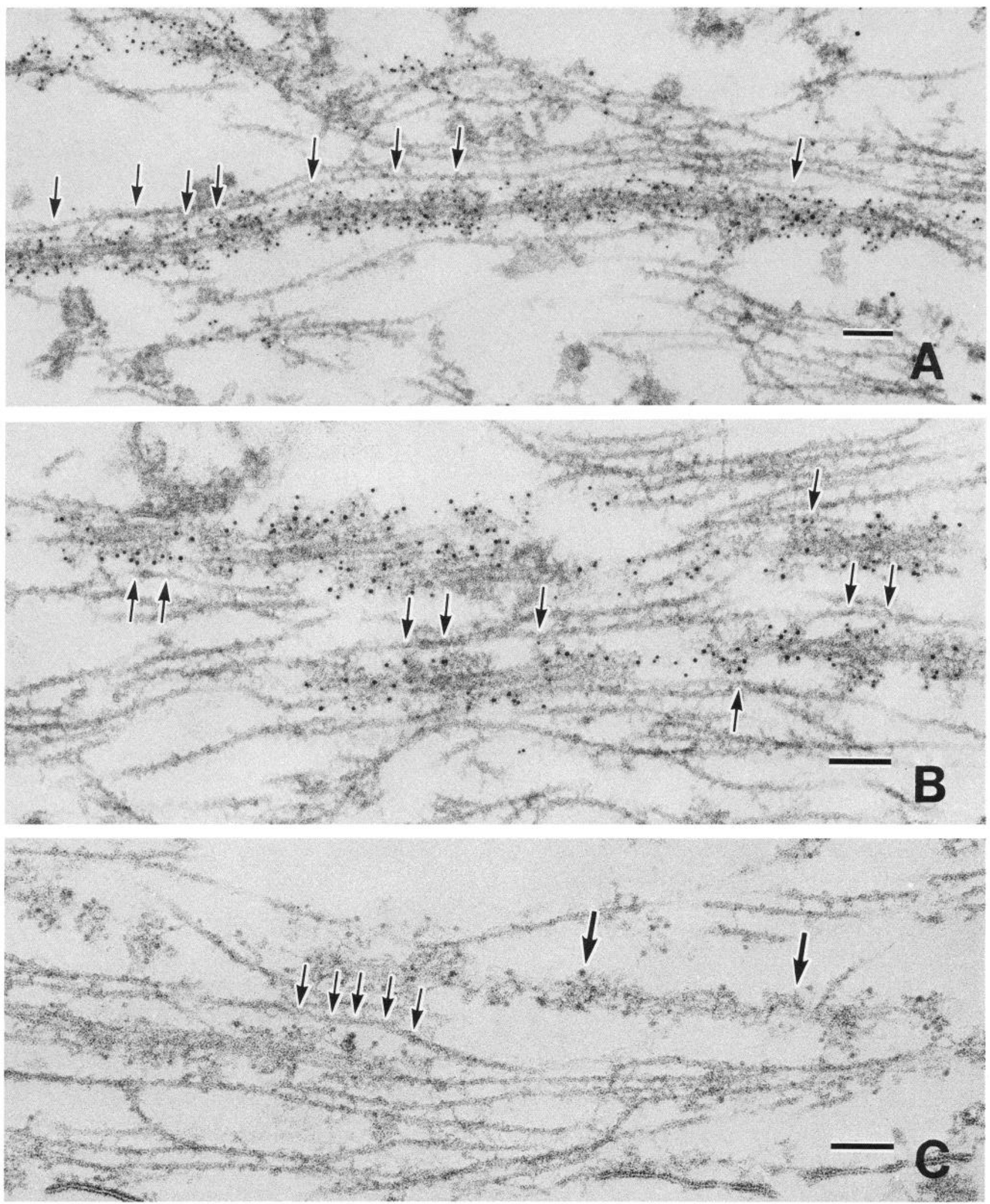

Figure 4. Higher-magnification views of motor neuron dendrites stained with anti-MAP2 IgG and gold-labeled second IgG $(A, B)$ or ferritinlabeled second $\operatorname{IgG}(C)$. Numerous gold particles are observed on fuzzy structures between MTs and NFs (arrows, $A$ and $B$ ). Ferritin particles are studded on the strands between MT and NF (small arrows). Large arrows point to ferritin-immune complexes associated with MT cut tangentially to the MT surface. Scale bars, $0.1 \mu \mathrm{m}$. 


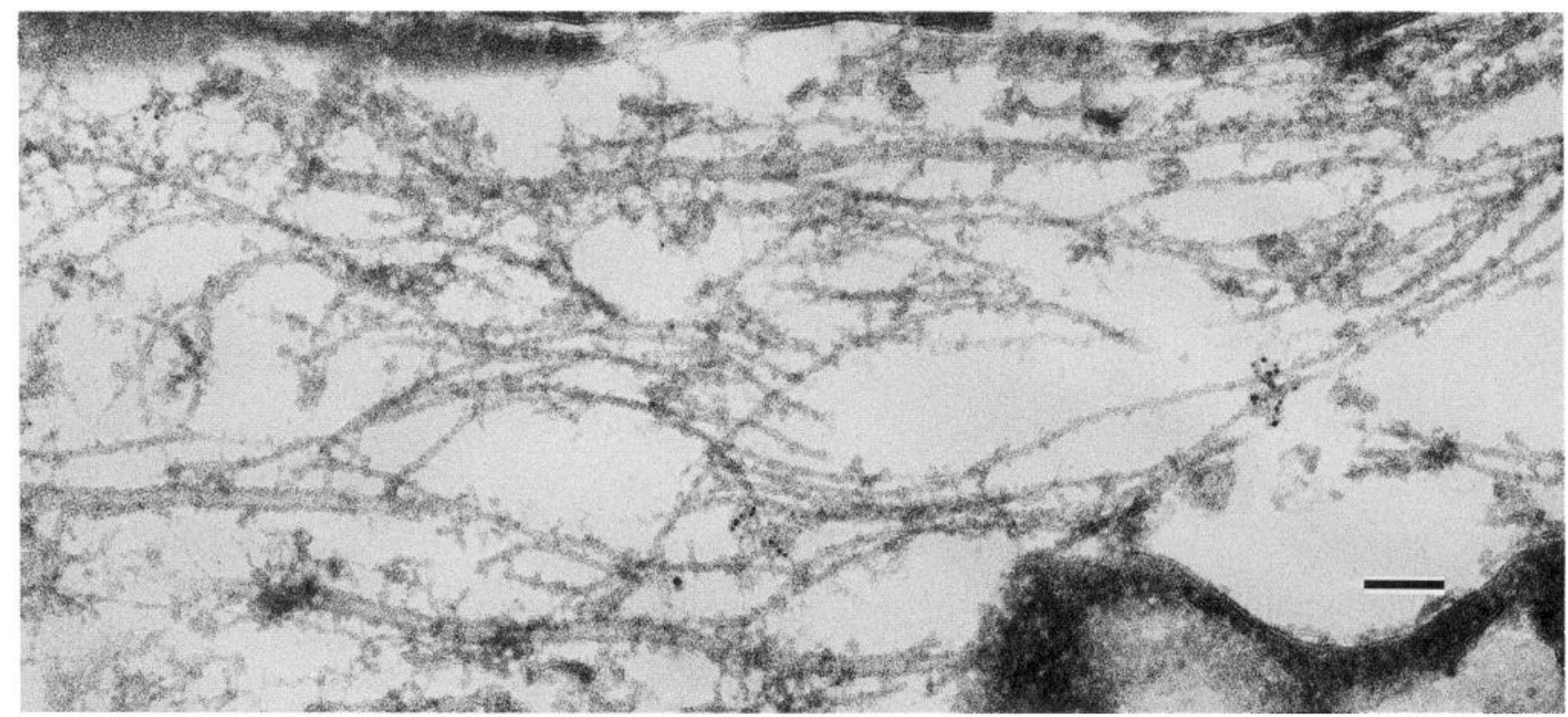

Figure 5. Motor neuron dendrite incubated with nonimmune IgG and gold-labeled second IgG. Gold particles are rare. Scale bar, $0.1 \mu \mathrm{m}$.

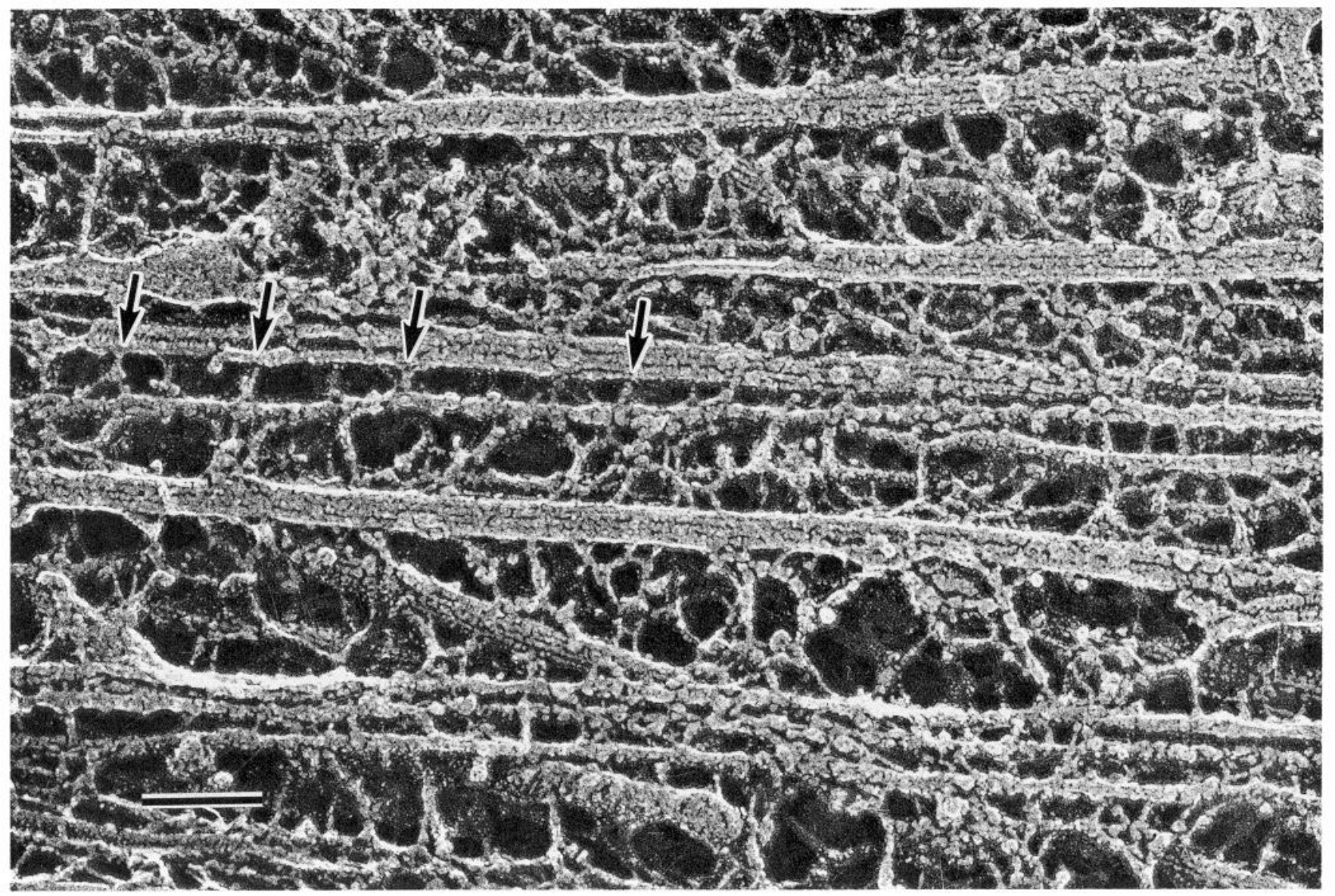

Figure 6. Quick-frozen, deep-etched dendrite of a motor neuron in unfixed spinal cord. NFs exist as a single filament or small fascicles (lower part of the figure) along with MTs. Crossbridges between MT and NF are apparent (arrows). Scale bar, $0.1 \mu \mathrm{m}$. 


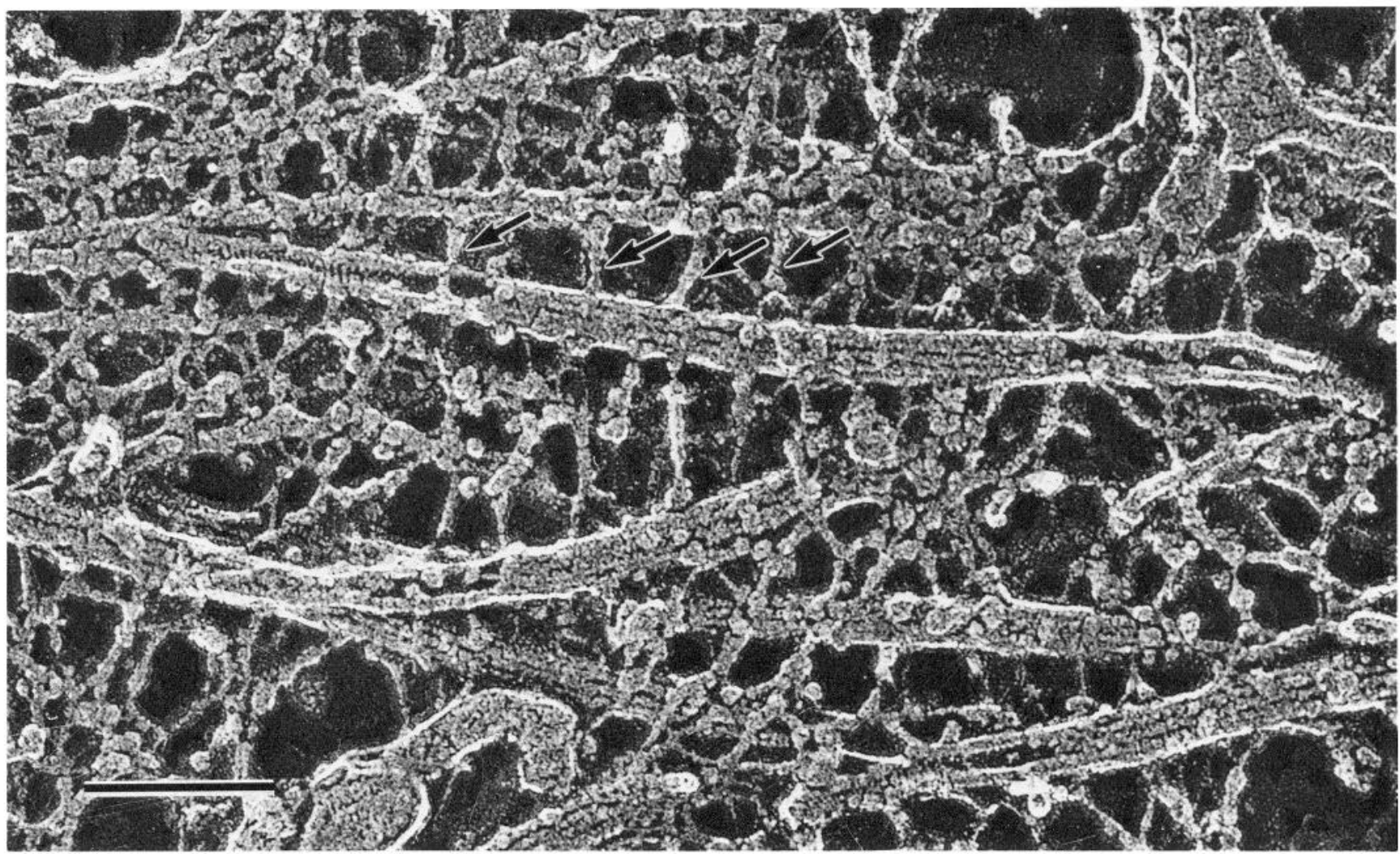

Figure 7. Higher-magnification view of cytoskeleton in a motor neuron dentrite clearly showing crossbridges between NF and MT (arrows). Scale bar, $0.1 \mu \mathrm{m}$.

fied by this column chromatography, fractions were further concentrated by precipitation by $50 \%$ ammonium sulfate. Concentration of purified MAP2 was $0.8 \mathrm{mg} / \mathrm{ml}$.

\section{In vitro assembly of $70 \mathrm{kDa}(\mathrm{L})$ protein, $M A P 2$, and tubulin}

Five kinds of experiments were carried out.

$1.400 \mu \mathrm{l}$ of $\mathrm{L}$ protein $(0.1 \mathrm{mg} / \mathrm{ml})$ in PEM $(0.1 \mathrm{M}$ Pipes, $1 \mathrm{~mm}$ EGTA, $1 \mathrm{mM} \mathrm{MgCl}$, pH 6.8) was incubated at $35^{\circ} \mathrm{C}$ for $30 \mathrm{~min}$.

2. $400 \mu \mathrm{l}$ of MAP2 $(0.25 \mathrm{mg} / \mathrm{ml})$ in PEM was incubated at $35^{\circ} \mathrm{C}$ for $30 \mathrm{~min}$.

3. $400 \mu \mathrm{l}$ of $\mathrm{L}$ protein $(1.0 \mathrm{mg} / \mathrm{ml})$ and MAP2 $(0.25 \mathrm{mg} / \mathrm{ml})$ was incubated at $35^{\circ} \mathrm{C}$ for $30 \mathrm{~min}$.

4. First $\mathrm{L}$ protein and MAP2 were incubated at $35^{\circ} \mathrm{C}$ for $30 \mathrm{~min}$ and then tubulin, GTP, and taxol were added to get $400 \mu \mathrm{l}$ of solution containing $1.0 \mathrm{mg} / \mathrm{ml} \mathrm{L}$ protein, $0.25 \mathrm{mg} / \mathrm{ml} \mathrm{MAP} 2,0.8 \mathrm{mg} / \mathrm{ml}$ tubulin, $1 \mathrm{mM}$ GTP, and $20 \mu \mathrm{M}$ taxol. This solution was further incubated at $35^{\circ} \mathrm{C}$ for $30 \mathrm{~min}$.

5. $\mathrm{L}$ protein was first incubated at $35^{\circ} \mathrm{C}$ for $30 \mathrm{~min}$ and then tubulin, GTP, and taxol were added to get $400 \mu \mathrm{l}$ of solution containing $1.0 \mathrm{mg} /$ $\mathrm{ml} \mathrm{L}$ protein, $0.8 \mathrm{mg} / \mathrm{ml}$ tubulin, $1 \mathrm{~mm}$ GTP, and $20 \mu \mathrm{M}$ taxol. This solution was further incubated at $35^{\circ} \mathrm{C}$ for $30 \mathrm{~min}$.

The solutions were divided into 2 groups. The first group was used for analysis by QF-DE electron microscopy. The other group was used for SDS-PAGE analysis. All the solutions were centrifuged at 120,000 $\times g$ at $30^{\circ} \mathrm{C}$ for $30 \mathrm{~min}$. The pellets of one group, if present, were immediately quick-frozen, deep-etched as described previously (Hirokawa et al., 1985). In the second group the supernatants were stored and the pellets were resuspended to get the original volume $(200 \mu \mathrm{l})$ with PEM buffer. Then the same amounts of supernatants and pellets of suspensions were analyzed by SDS-PAGE using $7.5 \%$ polyacrylamide running gel.

For another experiment (1) L protein $(1.0 \mathrm{mg} / \mathrm{ml}),(2)$ MAP2 $(0.8 \mathrm{mg} /$ $\mathrm{ml})$, and (3) L protein $(1.0 \mathrm{mg} / \mathrm{ml})$ plus MAP2 $(0.8 \mathrm{mg} / \mathrm{ml})$ were suspended in $200 \mu$ l of PEM containing $0.6 \mathrm{M} \mathrm{NaCl}$, incubated for $30 \mathrm{~min}$ at $35^{\circ} \mathrm{C}$ and centrifuged at $120,000 \times g$ for $30 \mathrm{~min}$ at $30^{\circ} \mathrm{C}$. The su- pernatants and pellets were analyzed by SDS-PAGE using $7.5 \%$ polyacrylamide running gel as mentioned above.

\section{Protein determination}

Protein concentrations were estimated by the assay of Bradeford et al. (1976).

\section{Results}

Antibody characterization

Figure 1 shows an immunostaining of rat brain crude extracts and rat brain MT proteins by the affinity-purified PcAb and nonimmune IgG. The PcAb recognized the bands of MAP2 on every blot, while it did not cross-react with MAP1.

\section{Immunofluorescence microscopy}

Anti-MAP2 PcAb stained cell bodies and dendrites of motor neurons at the anterior horn region, but it did not stain axons in the white matter (Fig. 2).

\section{Immunoelectron microscopy}

Figure 3 displays a low-power photomicrograph of a dendrite of a motor neuron stained with anti-MAP2 IgG and gold-labeled second $\mathrm{Ab}$. In the dendrites of the motor neuron, neurofilaments were relatively abundant compared with the dendrites of other nerves. Neurofilaments very often ran near the microtubules, and crossbridges connected these neurofilaments to the microtubules. Thus, these dendrites are suitable for studying the chemical nature of crossbridges between neurofilaments and dendrites.

It could be clearly observed that gold particles were localized 

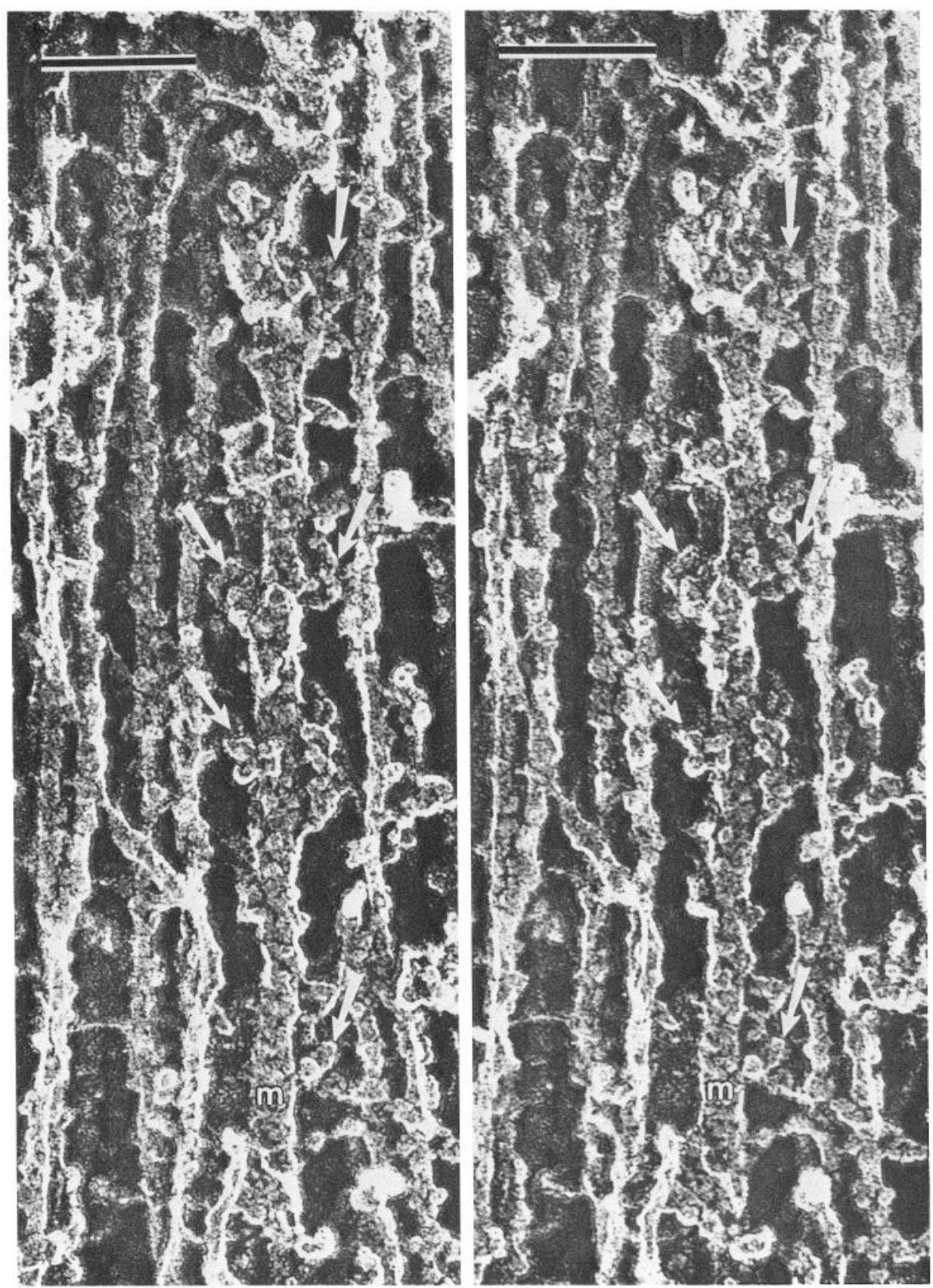

Figure 8. Stereopair of cytoskeletons in a dendrite incubated with anti-MAP2 $\mathrm{IgG}$ and ferritin-labeled second $\mathrm{IgG}$. Ferritin-IgG complexes decorate crossbridges between MTs $(m)$ and NFs $(a r-$ rows). on fuzzy structures associated with microtubules. Many such structures crosslinked neurofilaments with microtubules (Figs. $2,3)$. Figure $4, A$ and $B$, highlights fuzzy filamentous structures decorated with gold particles between microtubules and neurofilaments. When ferritin-labeled second $\mathrm{Ab}$ was also used, as Figure $4 C$ demonstrates, ferritin particles were localized on fuzzy structures between neurofilaments and microtubules. In control samples, gold particles were rarely observed (Fig. 5). These results were further confirmed by antibody decoration in situ in conjunction with QF-DE.

Figures 6 and 7 show unfixed motor neuron dendrites after QF-DE. As can be seen, neurofilaments tended to run singly, in pairs, or as a small fascicle adjacent to microtubules. Crossbridges (25-50 $\mathrm{nm}$ long, 4-6 $\mathrm{nm}$ wide) were clearly recognizable between microtubules and neurofilaments. After weak fixation for antibody decoration, the protofilament structures on the surface of MTs could not be observed, while MT could be easily identified by the width of filaments. In the sample incubated with anti-MAP2 IgG and ferritin-labeled second Ab, ferritin antibody complexes were found to decorate crossbridges between microtubules and neurofilaments heavily (Fig. 8), whereas crossbridges in the control specimen were not decorated (Fig. 9).

\section{Reconstitution study}

MAP2 bound to NFs assembled by L proteins. We attempted to assemble neurofilaments in vitro to determine whether neurofilaments are crosslinked with microtubules by MAP2 molecules. For this purpose we used neurofilaments from $\mathrm{L}$ proteins only, because $\mathrm{H}$ proteins $(200 \mathrm{kDa})$ may also contribute as 
Figure 9. A stereopair of control preparations incubated with nonimmune IgG and ferritin-labeled second IgG. Crossbridges (arrows) between MTs $(m)$ and NFs are not decorated with ferritin-IgG complexes.
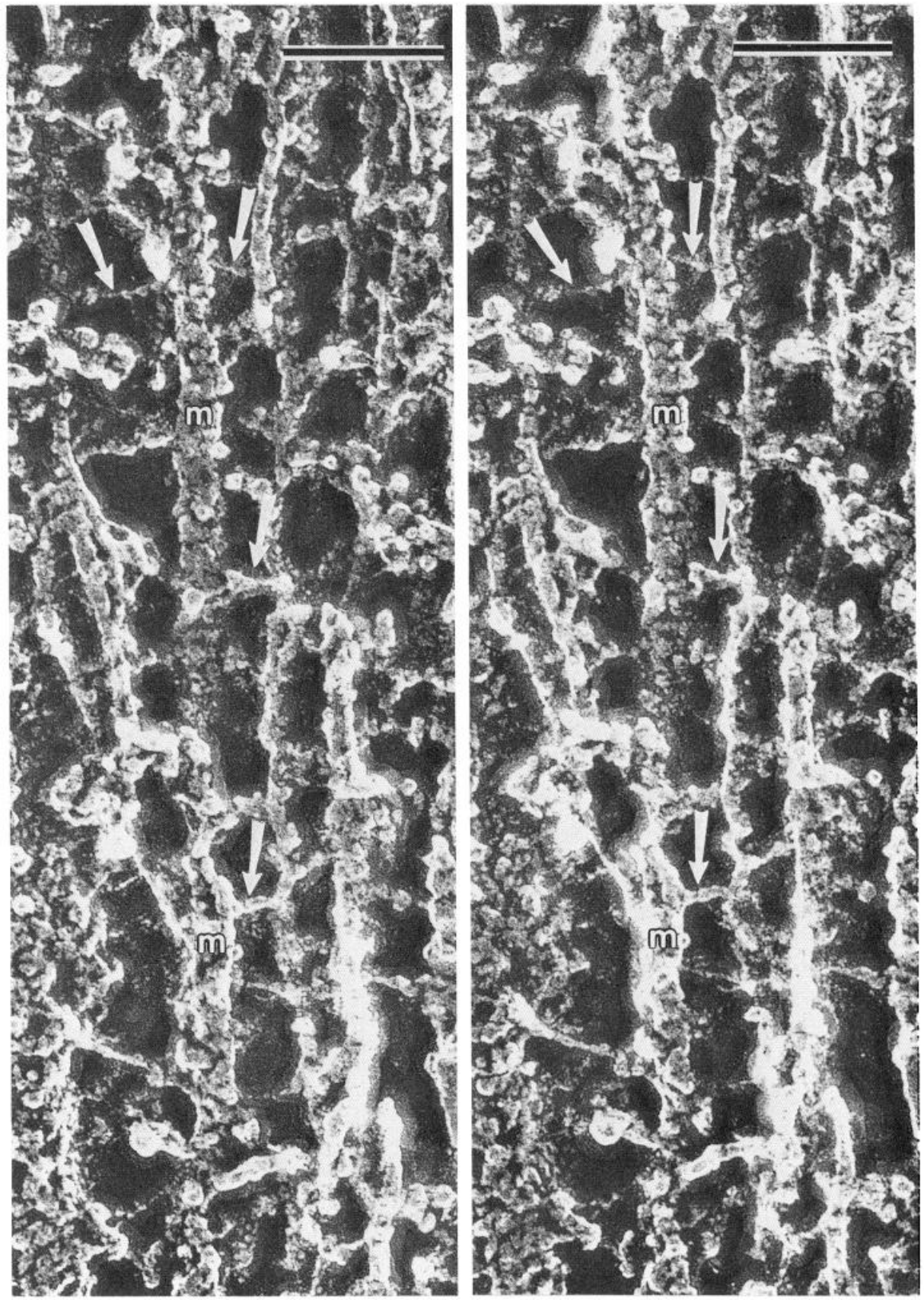

crossbridges between NFs and MTs (Minami and Sakai, 1983). We obtained purified L proteins from calf spinal cords from both anion-exchange DEAE column (Kotani et al., 1985) and Mono Q column chromatographies. After incubation at $35^{\circ} \mathrm{C}$ for $30 \mathrm{~min}$ and centrifugation, L proteins were detected only in pellets (Fig. 10A). These pellets revealed numerous intermediate filaments about $11 \mathrm{~nm}$ in diameter (Fig. 11A), although this diameter was not always regular, with very fine spines sometimes seen on the filament surface. However, we have never observed crossbridges such as those observed in samples containing L, MAP2, and tubulin (25-50 $\mathrm{nm}$ long, 4-6 nm wide: Fig. $11 D-F)$. When we added MAP2 to L proteins, most of MAP2 was present in the pellet as judged by SDS-PAGE (Fig.
10A). This pellet had many neurofilaments, but they were not packed as tightly as those in the pellet containing only $\mathrm{L}$ protein (Fig. 11C). The filaments were frequently decorated by knobby material, which could be MAP2 (Fig. 11A). MAP2 alone was not found in the pellet (Fig. 10A).

To determine if MAP2 molecules were trapped in the network of $\mathrm{L}$ neurofilaments and sedimented in the pellet, we carried out the same experiment in the presence of high salt $(0.6 \mathrm{M}$ $\mathrm{NaCl}$ ). Under these conditions, MAP2 was present mostly in the supernatant, while L protein was detected in the pellets of the suspension containing both L protein and MAP2 (Fig. 10B). $\mathrm{L}$ protein formed filaments under these conditions as well (see Fig. 11A). These results indicate that MAP2 was not trapped in 

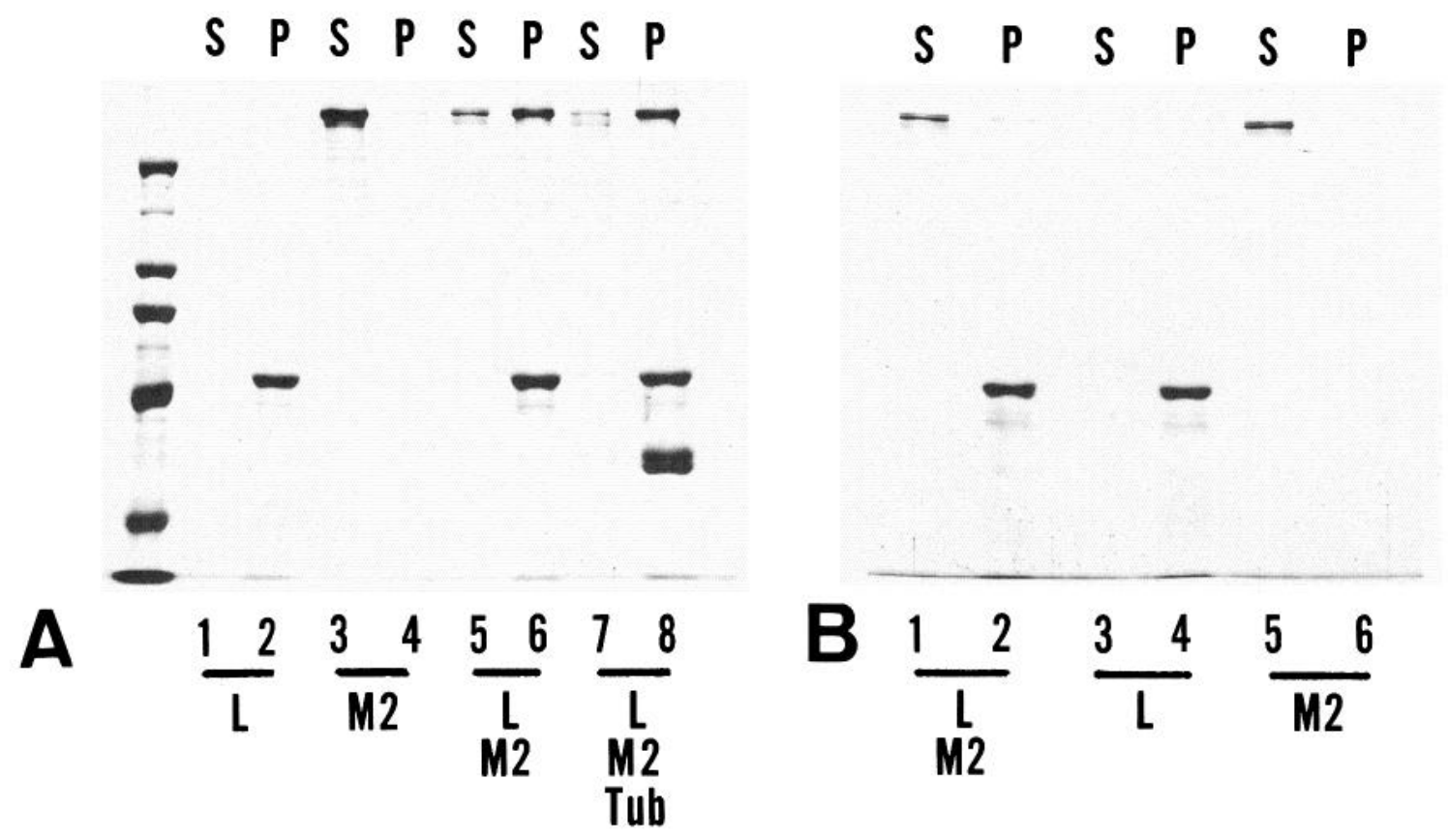

Figure 10. SDS-PAGE analysis of supernatants and pellets of reconstitution study. A, Unnumbered lane: Molecular-weight standards (prominent bands reading down): myosin (200 kDa), beta-galactosidase (116 kDa), phosphorylase B (92 kDa), BSA (66 kDa), ovalbumin (45 kDa). Lanes 1 and 2; supernatant and pellet of L protein after incubation; lanes 3 and 4: supernatant and pellet of MAP2 after incubation; lanes 5 and 6: supernatant and pellet of L protein plus MAP2 after incubation; lanes 7 and 8: supernatant and pellet of L protein plus MAP2 plus tubulin after incubation. $B$, Supernatant and pellet of proteins incubated in PEM containing high salt $(0.6 \mathrm{M} \mathrm{NaCl})$. Lanes 1 and 2 : supernatant and pellet of $\mathrm{L}$ protein plus MAP2; lanes 3 and 4: supernatant and pellet of L protein; lanes 5 and 6: supernatant and pellet of MAP2. $S$, supernatant; $P$, pellet; $L$, $70 \mathrm{kDa}$ protein; $M 2$, MAP2; Tub, tubulin.

the network of neurofilaments nonspecifically, and they support the concept that under normal conditions MAP2 specifically bound to neurofilaments composed of $\mathrm{L}$ protein.

\section{MAP2 formed crossbridges between NFs and MTS}

When we first formed neurofilaments with $\mathrm{L}$ protein and then added tubulin in the presence of $1 \mathrm{mM}$ GTP and $20 \mu \mathrm{M}$ taxol, we found numerous NFs and MTs packed together in the pellets (Fig. $11 B$ ). In this case $\mathrm{L}$ protein and tubulin existed only in the pellet (Fig. 10). Prominent crossbridges were not observed between NFs and MTs. Interestingly, NFs and MTs tended to form respective domains, but at boundaries certain areas where both elements were mixed could easily be discerned (Fig. 11B).

When L protein was incubated with MAP2 and then tubulin was added with $1 \mathrm{mM}$ GTP and $20 \mu \mathrm{M}$ taxol, L protein, MAP2, and tubulin were detected mostly in the pellet (Fig. 10A). In QF-DE replicas of these pellets we found that MTs and NFs were not packed tightly, as in the L protein and tubulin pellet; also NFs were linked with MTs via many crossbridges (25-50 $\mathrm{nm}$ long, 4-6 nm wide), exactly like those found in vivo (Figs. $6,7,11 D-F$,). Of course, in these pellets MTs were connected via crossbridges with each other as well.

\section{Discussion}

The present study demonstrated that antibody against MAP2 stained crossbridges linking NFs to MTs in vivo by the immunogold method and antibody decoration in conjunction with QF-DE electron microscopy. In addition, our reconstruction study showed that MAP2 formed crossbridges between MTs and NFs composed of $\mathrm{L}$ protein. These in vivo and in vitro approaches strongly support the idea that MAP2 is a component of crossbridges between NFs and MTs in the neuronal cytoskeleton.

In the reconstitution study, we used only $\mathrm{L}$ protein to form NFs because of the possibility that long carboxy terminals of $200 \mathrm{kDa}(\mathrm{H})$ and $145 \mathrm{kDa}(\mathrm{M})$ proteins may also form crossbridges between NFs and MTs and because it has been shown in a binding study of ${ }^{32} \mathrm{P}$-labeled MAPs to NFs, which were transferred electrophoretically to nitrocellulose, that, of the 3 neurofilament proteins, only L protein bound MAPs (Heimann and Liem, 1985).

Previous in vitro experiments have demonstrated that highmolecular-weight (HMW) MAPs bound to neurofilaments, and when these MAP-decorated filaments were added to microtubules made from pure tubulin, a viscous complex was rapidly formed, indicating that HMW MAPs might crosslink NFs with MTs (Leterrier et al., 1982; Williams and Aamodt, 1985). Furthermore, cAMP-dependent protein kinase has been shown to be associated with MAP2 and phosphorylated $150 \mathrm{kDa}$ neurofilament protein (Leterrier et al., 1981). These in vitro data support our results that MAP2 is a component of crossbridges between MTs and NFs in vivo.

The possibility exists that the crossbridges between MTs and NFs in vivo are composed of complexes of HMW MAPs. However, because the crossbridges between MTs and NFs are mostly simple in shape (4-6 nm diameter, 25-50 nm long) and MAP2 molecules are flexible rodlike structures $100 \mathrm{~nm}$ in length (Voter and Erikson, 1982; Gottlieb and Murphy, 1985; Hirokawa, 1986) and form periodic arm-like projections on microtubule surfaces (Kim et al., 1979), and, further, because we found that MAP2 alone formed crossbridges in vitro resembling those in vivo between NFs and MTs, we believe that MAP2 alone could form crossbridges in vivo. However, our results do not rule out the 

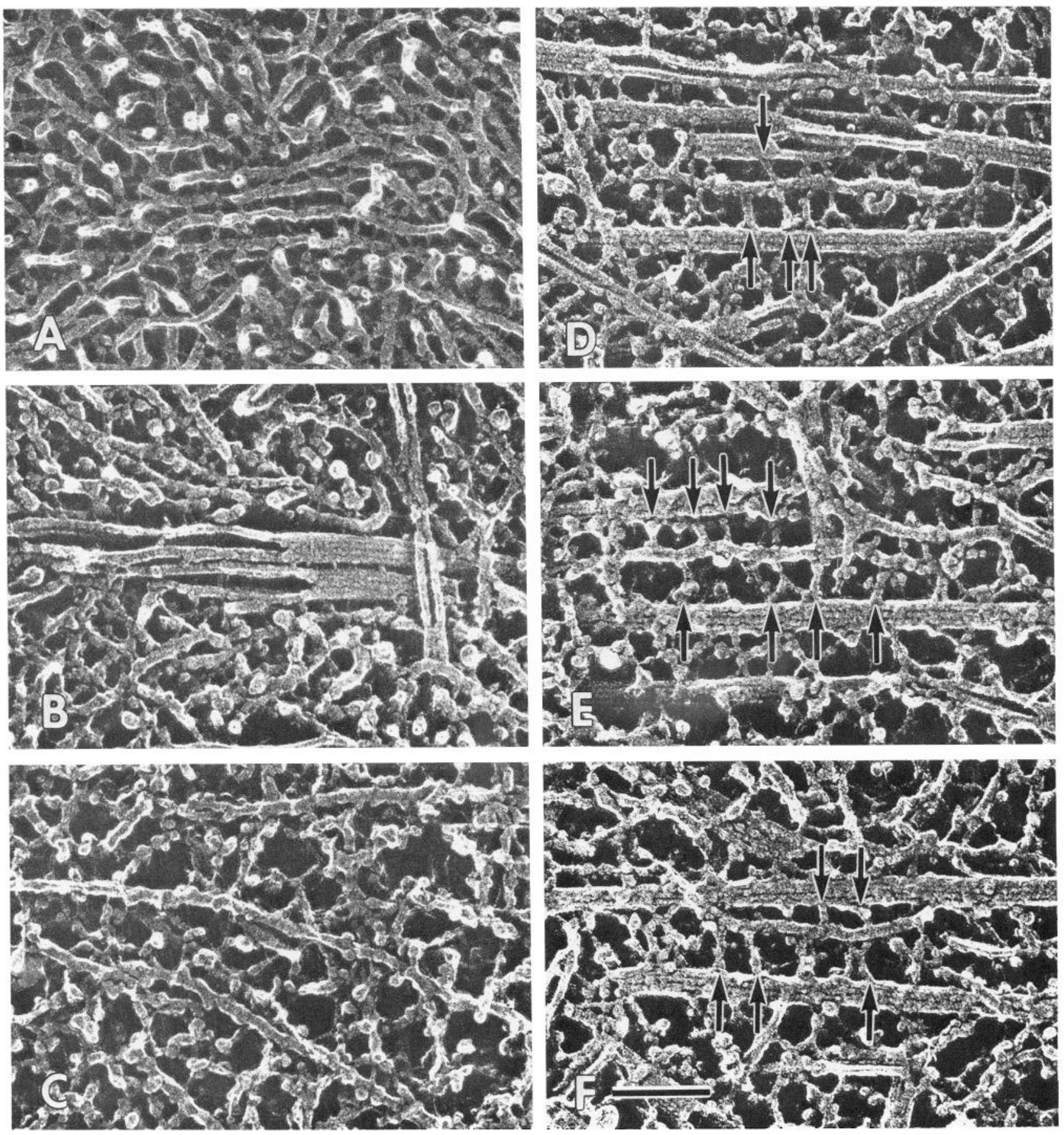

Figure 11. QF-DE pellets of reconstitution study. A, Pellet of $\mathrm{L}$ protein. L protein forms very tightly packed NFs. $B$, Pellet of $\mathrm{L}$ protein plus tubulin polymerized into MTs in the presence of taxol and GTP. MTs and NFs are packed together, but there are no crossbridges between them $C$, Pellet of $\mathrm{L}$ protein plus MAP2. NFs are formed. Knobby materials are frequently attached to the filaments. $D-F$. Pellets of $\mathrm{L}$ protein plus MAP2 plus tubulin. NFs are linked with MTs by several crossbridges (arrows). Crossbridges between MTs are also observed. Scale bar, $0.1 \mu \mathrm{m}$.

possibility that neurofilament $200 \mathrm{~K}$ and/or $145 \mathrm{~K}$ proteins may play a role in other types of crossbridges between MTs and NTs in the neuronal cytoskeleton. Because the amount of MAP2 in the axon is low (Bernhand and Matus, 1984; Hirokawa et al., 1985), neurofilament proteins may contribute as additional crossbridges between MTs and NFs. This scenario is supported by data that purified NFs stimulated MT assembly and caused gelation (Minami and Sakai, 1983). This problem will require further attention, probably with an approach similar to that employed in the present study.

Little is known concerning the regulatory mechanisms of the linkage between MTs and NFs. In the case of actin, in vitro studies have demonstrated that mixtures of purified actin, purified tubulin, and purified HMW MAPs (principally MAP2) formed networks (Selden and Pollard, 1983; Pollard et al., 1984). It has also been reported that phosphorylation of MAPs and 
$\mathrm{Ca}^{2+}$ and calmodulin regulate the interaction between M $\Lambda$ Ps and actin filaments (Nishida et al., 1981; Selden and Pollard, 1983; Kotani et al., 1985; Sobue et al., 1985). A similar mechanism may be at work in the regulation of MAP2-containing crossbridges between MTs and NFs. Clarification of these mechanisms in vivo will be an object of future study.

\section{References}

Bernhard, R., and A. Matus (1984) Light and electron microscopy studies of the distribution of microtubule-associated protein 2 in rat brain: A difference between dendritic and axonal cytoskeletons. J. Comp. Neurol. 226: 203-221.

Bloom, G. S., and R. B. Vallee (1983) Association of microtubuleassociated protein 2 (MAP2) with microtubules and intermediate filaments in cultured brain cells. J. Cell Biol. 96: 1523-1531.

Bradeford, M. M. (1976) A rapid and sensitive method for the quantitation of microgram quantities of protein utilizing the principle of protein-dye binding. Anal. Biochem. 72: 248-254.

Ellisman, M. A., and K. R. Porter (1980) Microtrabecular structure of the axoplasmic matrix: Visualization of cross-linking structures and their distribution. J. Cell Biol. 87: 464-479.

Geisler, N., and K. Weber (1981) Self-assembly in vitro of the 68,000 molecular weight component of the mammalian neurofilament triplet proteins into intermediate-sized filaments. J. Mol. Biol. 151: 565571.

Gottlieb, R. A., and D. B. Murphy (1985) Analysis of the microtubulebinding domain of MAP2. J. Cell Biol. 101: 1782-1789.

Heimann, R. M., and M. L. Liem (1985) Microtubule-associated proteins bind specifically to the 70K-Da neurofilament protein. J. Biol. Chem1. 260: 12160-12166.

Heuser, J. E., and S. R. Salpeter (1979) Organization of acetylcholine receptors in quick-frozen, deep-etched, and rotary-replicated Torpedo postsynaptic membrane. J. Cell Biol. 82: 150-173.

Hirokawa, N. (1982) Cross-linker system between neurofilaments, microtubules, and membranous organelles in frog axons revealed by the quick-freeze, deep-etching method. J. Cell Biol. 94: 129-142.

Hirokawa, N. (1986) $270 \mathrm{~K}$ Microtubule-associated protein crossreacting with anti-MAP2 IgG in the crayfish peripheral nerve axon. J. Cell Biol. 103: 33-39.

Hirokawa, N., and J. E. Heuser (1981) Quick-freeze, deep-etch visualization of the cytoskeleton beneath surface differentiations of intestinal epithelial cells. J. Cell Biol. 91: 399-409.

Hirokawa, N., and Y. Yorifuji (1986) Cytoskeletal architecture in reactivaled crayfish axons with special reference to the crossbridges between microtubules and membrane organelles and among microtubules. Cell Motil. Cytoskel. 5: 458-468.

Hirokawa, N., M. A. Glicksman, and M. B. Willard (1984) Organization of mammalian neurofilament polypeptides within the neuronal cytoskeleton. J. Cell Biol. 98: 1523-1536.

Hirokawa, N., G. S. Bloom, and R. B. Vallee (1985) Cytoskeletal architecture and immunocytochemical localization of microtubuleassociated proteins in regions of axons associated with rapid axonal transport: The beta, beta'-iminodipropionitrile-intoxicated axon as a model system. J. Cell Biol. 101: 227-239.

Kim, H., L. I. Binder, and J. L. Rosenbaum (1979) The periodic association of MAP2 with brain microtubules in vitro. J. Cell Biol. 80: 266-276.

Kotani, S., E. Nishida, H. Kumagai, and H. Sakai (1985) Calmodulin inhibits interaction of actin with MAP2 and Tau, two major microtubule-associated proteins. J. Biol. Chem. 260: 10779-10783.
Laemmli, V. K. (1970) Cleavage of structural proteins during the assembly of the head of bacteriophage T4. Nature 227: 680-685.

Leterrier, J. F., R. H. Liem, and M. L. Shelanski (1981) Preferential phosphorylation of the 150,000 molecular weight component of neurofilament by a cyclic AMP-dependent, microtubule-associated protein kinase. J. Cell Biol. 90: 755-760.

Leterrier, J. F., K. H. Liem, and M. L. Shelanski (1982) Interactions between neurofilaments and microtubule-associated proteins: A possible mechanism for intraorganellar bridging. J. Cell Biol. 95: 982986.

Minami, Y., and H. Sakai (1983) Network formation by neurofilament-induced polymerization of tubulin: $200 \mathrm{~K}$ subunit of neurofilament triplet promotes nucleation of tubulin. J. Biochem. 94: 20232033.

Miyata, Y., M. Hoshi, Y. Nishida, Y. Minami, and H. Sakai (1986) Binding of microtubule-associated protein 2 and tau to the intermedicate filament reassembled from neurofilament $70 \mathrm{KDa}$ subunit protein. J. Biol. Chem. 261: 13026-13030.

Nishida, E., T. Kuwaki, and H. Sakai (1981) Phosphorylation of microtubule-associated proteins (MAPs) and $\mathrm{pH}$ of the medium control the interactions between MAPs and actin filaments. J. Biochem. (Tokyo) 90: 575-578.

Papasozomenos, S. C., L. I. Binder, P. K. Bender, and M. R. Payne (1985) Microtubule-associated protein 2 (MAP2) within axons of spinal motor neurons: Associations with microtubules and neurofilaments in normal and beta,beta'-iminodipropionitrile-treated axons. J. Cell Biol. 100: 74-85.

Pollard, T. D., S. C. Selden, and P. Maupin (1984) Interaction of actin filaments with microtubules. J. Cell Biol. 99: 33s-37s.

Selden, S. C., and T. D. Pollard (1983) Phosphorylation of microtubule-associated proteins regulates their interactions with actin filaments. J. Biol. Chem. 258: 7064-7071.

Shelanski, M. L., E. Gaskin, and C. R. Cantor (1973) Microtubules assembly in the absence of added nucleotides. Proc. Natl. Acad. Sci. USA 70: 765-768.

Shiomura, Y., and N. Hirokawa (1987a) The molecular structure of microtubule-associated protein IA (MAP1A) in vivo, and in vitro. An immunoelectron microscopy and quick-freeze, deep-etch study. J. Neurosci. 7: 1461-1469.

Shiomura, Y., and N. Hirokawa (1987b) Colocalization of MAP1 and MAP2 on the neuronal microtubule in situ revealed with doublelabelling immunoelectron microscopy. J. Cell Biol. 104: 1575-1578.

Sobue, K., T. Tanaka, N. Ashino, and S. Kakiuchi (1985) $\mathrm{Ca}^{+}$and calmodulin regulate microtubule-associated protein-actin filament interaction in a flip-flop switch. Biochem. Biophys. Acta 845: 366-372.

Towbin, H., T. Staehelin, and J. Gordon (1979) Electrophoretic transfer of proteins from polyacrylamide gels to nitrocellulose sheets: Procedure and some applications. Proc. Natl. Acad. Sci. USA 76:43504354.

Vallee, R. B. (1982) A taxol-dependent procedure for the isolation of microtubules and microtubule-associated proteins (MAPs). J. Cell Biol. 92: 435-442.

Voter, W. A., and H. P. Erikson (1982) Electron microscopy of MAP2. J. Ultrastruct. Res. 80: 374-382.

Weingarten, M. D., A. H. Lockwood, S. Y. Hwo, and M. W. Kirschner (1975) A protein factor essential for microtubule assembly. Proc. Natl. Acad. Sci. USA 72: 1858-1862.

Williams, R. C., and E. J. Aamodt (1985) Interactions between microtubules and neurofilaments in vitro. Ann. New York Acad. Sci. 455: 509-524. 